\title{
DIGNIDADE HUMANA E O DIREITO AO LAZER ENTRE UNIVERSITÁRIOS DO ALTO TIETE $\hat{~}^{1}$
}

\author{
Carla Alessandra Branca Ramos Silva Aguiar ${ }^{2}$ \\ Universidade de Mogi das Cruzes - UMC \\ Mogi das Cruzes - SP - Brasil \\ Luci Mendes de Melo Bonini ${ }^{3}$ \\ Universidade de Mogi das Cruzes - UMC \\ Mogi das Cruzes - SP - Brasil
}

RESUMO: Este estudo objetiva descrever a importância que os universitários atribuem ao lazer, assim como busca-se compreender como eles investem seu tempo disponível em atividades que lhes tragam descontração e bem estar, respeitando o princípio da dignidade humana. Para tanto realizou-se uma pesquisa descritiva de corte transversal, utilizando-se um questionário constituído de questões abertas e fechadas para apurar a realidade cotidiana dos entrevistados, alunos do curso Tecnólogo de Gestão em Recursos Humanos, período noturno de uma universidade particular da região do Alto Tietê. Os resultados encontrados sugerem que os universitários têm pouco tempo para o lazer e por isso aproveitam o tempo livre da semana, principalmente para descansar, estar com a família e fazer atividades que os façam relaxar e esquecer o estresse do dia a dia.

PALAVRAS-CHAVE: Atividades de Lazer. Políticas. Estudantes.

\section{HUMAN DIGNITY AND THE RIGHT TO LEISURE AMONG UNIVERSITY STUDENTS IN ALTO TIETÊ REGION - SÃO PAULO}

ABSTRACT: This study aims to describe the importance that college students tribute to leisure, and also look for a deep comprehension on how they invest their available time in activities that bring them relaxation and well being, respecting the principle of human dignity. For this descriptive study, was used a tool, developed for this purpose for the authors, consisting of open and closed questions to determine the daily reality of respondents which are all nighttime students of a Technological Course in Human Resources Management from a private university in the Upper Tietê River Region, in State of São Paulo, Brazil. All them work a great time along the day. The results suggest that students have little time for leisure, because of it they enjoy their free time on weekends, mainly to relax, to be with family and doing activities that do relax and forget the stress of their stressed.

\footnotetext{
${ }^{1}$ As autoras agradecem à Universidade de Mogi das Cruzes pela bolsa concedida para a elaboração da pesquisa.

${ }^{2}$ Mestre em Políticas Públicas pela Universidade de Mogi das Cruzes, docente do Curso de Direito na mesma universidade e membro do GRUPPU - Grupo de Pesquisas em Políticas Públicas.

${ }^{3}$ Doutora em Comunicação e Semiótica pela PUC-SP, Pesquisadora do Mestrado em Políticas Públicas e Líder do GRUPPU - Grupo de Pesquisas em Políticas Públicas.
} 
KEYWORDS: Leisure Activities. Policy. Estudants.

\section{Introdução}

Esta pesquisa apresenta parcialmente os resultados obtidos na dissertação de Mestrado "Dignidade Humana e o Direito ao Lazer entre universitários do Alto Tietê", apresentada ao Programa de Mestrado em Políticas Públicas da Universidade de Mogi das Cruzes, que objetivou descrever a importância que os universitários atribuem ao lazer, assim como buscou-se compreender como eles investiam seu tempo disponível em atividades que lhes trouxessem descontração e bem estar, respeitando, assim, minimamente, o princípio da dignidade humana.

A temporalidade, na vida dos seres humanos, é vista como essencial à condição da vida humana. Todos estes sistemas, no mundo contemporâneo, estão articulados a um único foco: viver, e neste contexto está o trabalho, ou a alguma atividade obrigatória, já que do trabalho decorre o sustento, a segurança e o abrigo, a manutenção da espécie e que, está relacionada com a "produção indireta do capital" (LUNARDI, 2010, p. 29).

O presente trabalho objetiva descrever o tempo destinado ao lazer de estudantes universitários, do período noturno, de um curso superior de Tecnologia em Recursos Humanos, de uma instituição de ensino superior privada da região do Alto Tietê, que fica no cone leste da Região Metropolitana de São Paulo (RMSP). Entende-se, aqui, que tanto o conceito de dignidade como o de lazer entram na composição da dignidade do trabalhador, resta, de ora em diante, apontar o perfil desses estudantes universitários, participantes da pesquisa e se o tempo gasto por eles no trabalho, no estudo e nos meios de transportes fere o princípio da dignidade humana e se o tempo que lhes resta é utilizado para atividades de lazer, e, se sim, quais as realizadas por estes estudantes durante esses momentos e que importância isto representa em suas vidas. 
Entre os universitários, em sua maioria na faixa dos 18 aos 28 anos, encontramse pessoas que trabalham oito horas por dia, se locomovem de casa para o trabalho, estudam, e, raramente, possuem tempo livre. Esses jovens, atualmente, quando não estão preocupados com a produtividade e o mundo do trabalho, estão buscando uma forma de adquirir mais competência para aumentar a produtividade, para buscar a melhoria das condições de vida e, no Brasil, a expansão do ensino superior nas duas últimas décadas vem testemunhando o avanço do desejo de aperfeiçoamento e da qualificação.

O foco normativo desta pesquisa, o direito ao lazer, surge: no inciso III e IV do Artigo $1^{\circ}$ da Constituição Federal de 1988: III - a dignidade da pessoa humana e IV - os valores sociais do trabalho, neste sentido, é preciso equilibrar trabalho e dignidade, e um destes componentes que auxiliam este equilíbrio é o descanso e o lazer. Assim, também, é assegurado ao trabalhador o lazer no artigo $6^{\circ}$. do mesmo diploma legal que afirma serem direitos sociais: a educação, a saúde, a alimentação, o trabalho, a moradia, o lazer, a segurança, a previdência social, a proteção à maternidade e à infância, a assistência aos desamparados. Os direitos sociais permitem às sociedades politicamente organizadas reduzir os excessos de desigualdade produzidos pelo capitalismo e garantir o mínimo de bem-estar para todos.

Calvet (s/d) afirma que os direitos fundamentais têm eficácia imediata, mas o direito ao lazer, dada a dificuldade de sua compreensão e a necessidade de conceitos sociológicos e de outras áreas, tem uma baixa normatividade, mesmo quando o legislador deixa explícita a ligação direta com o direito ao lazer, diz que o descanso semanal deve ser "preferencialmente aos domingos", ou seja, tornando regra para todos os mesmo dia da semana, de onde se depreende que fica mais fácil a sociabilidade, a 
reunião familiar e o usufruto de programas de lazer e entretenimento, mas nem sempre é assim, dadas as diferentes profissões e diferentes necessidades da sociedade atual.

O mesmo autor, (idem) afirma que a impossibilidade das flexibilizações de determinadas normas expostas na Consolidação das Leis do Trabalho (CLT) ainda dificulta sua compreensão, mas mesmo diante da complexidade dos centros urbanos, reconhece-se a necessidade de limitação dos horários de trabalho e o direito ao gozo do lazer, da mesma forma que exige novas especializações e novas formas de capacitação para o enfrentamento de diferentes tipos de trabalho que surgem a cada dia (CALVET, $\mathrm{S} / \mathrm{D})$.

Tendo este panorama em vista, este trabalho busca lançar luz às seguintes questões: Como o lazer participa do conceito de dignidade humana e dignidade do trabalhador, principalmente do trabalhador estudante universitário? Qual o perfil deste estudante universitário que trabalha e que tem reduzidos momentos de lazer? Quais as atividades mais comuns de lazer de estudantes universitários e que importância tem o lazer na vida desses sujeitos?

\section{Dignidade Humana e Dignidade do Trabalhador: Evolução de Conceitos e Normas}

Nos dias atuais, os seres humanos dos grandes centros urbanos, principalmente, têm plena convicção de que o progresso não deve ser empregado para a satisfação de poucos e o desprezo de muitos, mas não é esse o quadro que se configura, pois o sujeito é explorado para produzir cada vez mais, consumir cada vez mais, para os lucros de quem detém o poder econômico, que determina o critério de hierarquia das classes sociais (BACAL, 1988).

Isso corresponde dizer, que muitas vezes as pessoas se tornam escravas de suas próprias rotinas sem perceber quão prejudicial corresponde esse mecanismo, que os 
deixa engessados, buscando cada vez mais, para atender o capitalismo desenfreado, sem, ao menos, refletir sobre sua dignidade.

Etimologicamente a palavra dignidade deriva do latim dignitate, que tem o sentido de virtude, autoridade moral, honra, respeitabilidade. A dignidade envolve um conceito de qualidade de vida que envolve qualidade no trabalho e no lazer. A humanidade sempre teve no trabalho sua forma de subsistência, desde os primórdios com o extrativismo vegetal, a caça e a pesca, porém, na medida em que a população avança e a fome na mesma proporção, cultivar e criar o próprio alimento, passou a demandar mais tempo.

A civilização grega, que fundamenta a civilização ocidental, entendia o ócio como um tempo de criatividade, um tempo livre para praticar atividades de natureza intelectual e espiritual, ou seja, o tempo que constitui a forma mais elevada de vida, o ideal de sabedoria, para eles apenas os homens livres tinham dignidade (BACAL, 1988). Entre eles, foi Hesíodo que afirmou que o trabalho era para a subsistência humana e para o desenvolvimento espiritual ou das virtudes humanas (VIEIRA, 2010).

As sociedades anteriores à sociedade pós-revolução industrial teve, a grosso modo, o mesmo modelo: para a sociedade romana e, posteriormente, para os nobres e burgueses da Idade Média, a vida era distante do trabalho exaustivo, pois este era destinado aos escravos ou servos. A elite sempre teve muitos momentos de ócio e lazer, diferente dos servos e escravos que eram impedidos de terem pausas, a não ser aquelas impostas pelas intempéries, e ficavam, então, restritos a poucos momentos de festas e comemorações ditadas pelas religiões predominantes de seus governantes (STUCHI, 2011).

Foi somente com a Encíclica Rerum Novarum, quase no alvorecer do século XX, em 1891, que o trabalho é reconhecido tal como fizera Hesíodo, como meio de 
provimento e aprimoramento da personalidade e aperfeiçoamento humano (VIEIRA, 2010). A atitude do Papa Leão XIII, autor da bula papal em destaque, vai ao encontro do cenário da Revolução Industrial: o trabalho enobrece o homem, e, assim, se instauraria entre os séculos XVIII e XIX, a produção em larga escala que sobrecarregou os trabalhadores elevando os índices de estresse e cansaço o que fez com que as manifestações contrárias às ininterruptas horas de trabalho durante este período desse início a uma reflexão sobre o tempo livre, ou o lazer (QUEIROZ E SOUZA, 2009; SOUZA E MISAILIDIS, 2012)

Essa percepção do lazer advém, por sua vez, da precariedade da situação dos trabalhadores em relação a seus patrões, dá início às associações profissionais que exaltavam a greve como forma de educar os trabalhadores, de reivindicar e de obter melhorias relacionadas à jornada de trabalho mais curtas, mais segurança para os trabalhadores e outras formas de proteção, que irão dar início ao modelo de proteção social atual (ARRETCHE, 1995; BARROS, 2011).

$\mathrm{O}$ alvorecer do século $\mathrm{XX}$ trouxe os horrores das guerras mundiais, principalmente no que tange ao trabalho forçado nos campos de concentração e é a Declaração Universal dos Direitos Humanos (DUDH), de 1948, que efetiva a sua positivação (SOUZA E MISAILIDIS, 2012). As autoras ainda afirmam que a valorização do lazer consagra a efetivação dos direitos fundamentais por meio do desenvolvimento e fortalecimento das relações familiares e sociais, da igualdade e da cidadania e mais especificamente da criatividade e da personalidade humana.

No Brasil, a preocupação normativa com a dignidade do trabalhador tem início em 1930 na política de Getúlio Vargas com a criação, em 1930, do Ministério do Trabalho e com a Constituição de 1934 que se preocupam com a política do salário mínimo, o repouso remunerado, a jornada de trabalho de oito horas, férias remuneradas, 
e a regulamentação do trabalho feminino e dos menores no âmbito industrial. todo este aparato legal vai se materializar em 1943, com a criação da Consolidação das Leis Trabalhistas (CLT) (COUTO, 2004).

Nesta esteira, o trabalhador reconhecidamente com um papel importante no desenvolvimento do país, obteve mais avanços para a garantia de sua dignidade, pois a Constituição de 1946 manteve o princípio de cooperação dos órgãos sindicais e diminuiu o controle dos mecanismos do Estado aos sindicatos e seus adeptos, trazendo mais liberdades para negociações de interesses coletivos (ALVES, 2012).

Os períodos que seguem: i) o desenvolvimentista, entre 1956 a 1961 apenas manteve as garantias já institucionalizadas, aprimorando alguns pontos mais específicos na regulamentação das aposentadorias e ii) a ditadura militar uniformizou a previdência, mas reprimiu as representações sindicais, proibiu as greves e os direitos de reivindicação do trabalhador por melhores condições de trabalho e, consequentemente, de vida (VIANNA, 2006).

Esta síntese apertada demonstra que os trabalhadores brasileiros não tiveram uma maior reflexão sobre o lazer, mas as pressões pelo emudecimento dos sindicatos, e as greves que eclodiram na década de 70 foram, entre os vários elementos detonadores do movimento pela redemocratização do país, acontecimentos importantes para a melhoria da qualidade de vida dessa classe no Brasil.

Finalmente, em 1988, assistiu-se à promulgação da Constituição Federal que vislumbrava a dignidade humana como o foco da norma constitucional. Os direitos e garantias individuais, o Estado de Proteção Social floresceu no Brasil e os trabalhadores ganharam artigo 170 deste diploma legal que preceitua que a ordem econômica tem por fim assegurar a existência digna (POCHMANN, 2004). 
Desta forma, o termo dignidade humana é um complexo de direitos e deveres que asseguram a pessoa tanto contra todo e qualquer ato desumano ou ainda no sentido de garantir uma vida saudável, permitindo a participação em sociedade. O conceito de dignidade da pessoa humana é complexo, de natureza multifacetada e de fronteiras borradas que exigem em diferentes contextos diferentes sentidos de dignidade (SARLET, 2012). Assim, o conceito de lazer, como previsto pela Constituição Federal, participa do conceito de dignidade humana, pois ao ser valorizado pela norma maior do Estado passa a fazer parte do rol dos direitos fundamentais tutelados pelo Estado (SOUZA e MISAILIDIS, 2012).

O lazer, como uma face fundante da dignidade humana precisa ter asseguradas as condições para sua realização, assim como o trabalho e demais direitos e garantias individuais pois eles são a viga mestra para a qualidade de vida, e o lazer, é entre todos, definido como fonte de prazer pessoal, logo um recurso que melhora a qualidade de vida (CANTORANI, PEDROSO e PILATTI, 2009)

O ser humano, não pode ser manipulado pelo capitalismo exacerbado, pois o trabalho é um direito universal por isso deve estar fundamentado na dignidade da pessoa humana. Sendo assim, o trabalho deve ser prestado em condições dignas, de localidade, higiene, segurança, para atender ao fim esperado em si mesmo (DELGADO, 2006). E, claro, neste sentido, o direito social ao trabalho envolve o direito de acesso a uma profissão e ao preparo a uma vida profissional com vistas à melhoria das condições sociais do trabalhador.

\section{A importância do Lazer para a Dignidade do Trabalhador}

Para conceituar lazer precisamos primeiramente nos remeter a sua origem, lazer vem do verbo latino "licere", que significa ser lícito, legítimo, correto, próprio; por 
extensão, livre, espontâneo, em espanhol lazer é "ócio", esta última igualmente existente em português e significa fruto do descanso (AQUINO e MARTINS, 2007).

O Lazer é uma corrente de estudo interdisciplinar, tendo seus primeiros aprofundamentos no Brasil a partir da década de 1970. Dumazedier (1976) foi um dos primeiros a discutir o lazer no campo das Ciências Sociais, criando os primeiros tratados de Sociologia do Trabalho que abordavam Lazer e Sociologia do Lazer. Estas primeiras colocações consideravam tempo de não-trabalho como um tempo propício ao lazer ou tempo para o ócio.

Mas, conforme ressalta Marcellino (2012), foi preciso esperar até as primeiras décadas deste século para que se desenvolvesse um estudo sistemático da questão do lazer, tanto nos Estados Unidos, como na Europa. Foi a partir dos anos 50 que o lazer passa a ser objeto de estudo sistemático nas modernas sociedades urbano-industriais, quer capitalistas, quer socialistas, merecendo destaque o sociólogo francês já citado.

A partir de então, por um lado houve uma gradativa humanização do trabalho, a redução da jornada e a valorização do trabalhador, por outro, exige-se mais qualificação profissional e maior produtividade em menos tempo com menor custo, o que por seu turno prejudica a qualidade de vida do sujeito (CANTORANI, PEDROSO e PILATTI, 2009).

Já em 1976, Dumazedier afirmava que o primeiro estudo brasileiro foi do escritor Jose Acácio Ferreira em 1959 em Salvador, chamado de "Lazer Operário", ou seja, o lazer promovido pela classe trabalhadora no tempo de não-trabalho, entrelaçando as mediações de cultura de massa e cultura da elite, nas relações sociais e de trabalho (DUMAZEDIER, 1976). E é de 1932, que Bertrand Russel ${ }^{4}$ em seu Elogio do lazer, 1957 (apud DUMAZEDIER, 1976) deixou um importante referencial teórico sobre o

\footnotetext{
${ }^{4}$ Russel, Bertrand. O Elogio do Lazer. Rio de Janeiro: Companhia Nacional, 1957.
} 
consumo de bens materiais e culturais, entendendo que trabalhar demais causava danos imensos às sociedades modernas, e que o uso adequado do lazer poderia conduzir à felicidade (LUNARDI, 2010).

Lazer e recreação são reconhecidos como direitos urbanísticos e, obviamente, se relacionam com as condições de trabalho digno, qualidade de vida e podem ser entendidos como repouso, divertimento, direito ao esporte, no sentido de fôlego após o trabalho (MIRAGLIA, 2010).

Claro está, que o lazer está intrinsicamente ligado à satisfação própria e, obviamente, está conectado ao trabalho, não como opostos, mas como complementares.

No cenário da globalização e da produtividade, o progresso traz também novas formas de ocupar o tempo livre com atividades prazerosas, que podem afastar as rotinas, mas de qualquer forma, o lazer é sempre visto como um recurso para melhorar a qualidade de vida (CANTORANI, PEDROSO e PILATTI, 2009).

Lunardi (2010) menciona que há uma sobrecarga intensa do período de tempo vinculado a atividades obrigatórias, além do tempo destinado à manutenção da saúde, assim as certezas da modernidade estão sendo substituídas pelas incertezas sociais, vai daí que se depreende que todo o esforço empreendido pelo trabalhador na produção desenfreada no cenário capitalista, que a redução do tempo livre e as constantes exigências para maior qualificação vai mitigando seu tempo livre e consequentemente reduzindo suas chances de uma vida digna.

O lazer tem um peso grande na qualidade de vida do sujeito em função da sua multidimensionalidade, tanto do ponto de vista do sujeito, quanto do ponto de vista do ambiente profissional. $\mathrm{O}$ bem estar e a dignidade de um trabalhador advêm principalmente da forma como ele lida com seu tempo livre, das atividades e valores que atribui aos seus momentos de lazer. 
Qualidade de vida pode ser conceituada como aquela que oferece um mínimo de condições para que as pessoas possam desenvolver o máximo de suas potencialidades (CANTORANI, PEDROSO, PILATTI, 2009), assim também é a dignidade humana segundo Dal Col (s/d), pois ela é um vetor ontológico e paira sobre todas as ciências e, finalmente, inspira o ordenamento jurídico, inscreve o trabalho como um dos componentes deste conceito.

\section{Procedimento Metodológico}

O presente estudo é descritivo, de caráter quali-quantitativo, e com corte transversal, foi realizado no município de Mogi das Cruzes, Estado de São Paulo, numa Instituição de Ensino Superior (IES) privada na região do Alto Tietê. Esta região foi escolhida por ter um alto índice de Instituições de Ensino Superior (IES), privadas, as mais antigas, e públicas mais recentes e como há uma grande concentração populacional, favorece o um número significativo de IESs privadas, que atendem a muitos trabalhadores estudantes.

O estudo descritivo, segundo Dalfovo, Lana e Silveira (2008), tem como foco a compreensão do fenômeno à luz dos significados dos próprios sujeitos. Os autores afirmam que este tipo de pesquisa se configura dentro das análises quantitativas e qualitativas quando fazem um levantamento de dados e buscam os porquês dos mesmos.

Fizeram parte desse estudo 43 estudantes do curso de Tecnologia em Recursos Humanos, do período noturno, que trabalham e cursam o último semestre, na faixa etária de 18 a 50 anos entre homens $(M=32,56)$ e mulheres $(F=67,44)$. Esta opção deu-se em virtude de que estes, em breve, estarão no mercado de trabalho, gerenciando trabalhadores que apresentam doenças laborais, estresses advindos de metas altas de produtividades e de outras formas de pressões que sofrem os trabalhadores no cenário econômico global e nacional. 
Foi construído um questionário com o qual buscou-se delimitar o perfil do participante, identificando-se gênero, idade, qual ou quais suas atividades, se ele simplesmente estudava, estudava ou trabalhava, realizava afazeres domésticos. Buscouse identificar o tempo gasto em todas as ações realizadas pelos estudantes ao longo do dia e consequentemente, da semana. Em seguida as questões abertas buscaram identificar quanto tempo livre estes estudantes tinham na semana e por quais atividades eles optavam a fim de preencher, ou não, este tempo. As respostas dadas às questões fechadas foram tabuladas e o resultados expressos em porcentagens. As respostas dadas às questões abertas foram analisadas pela técnica de Análise de Conteúdo (BARDIN, 1977), as respostas agrupadas de acordo com um conjunto metassêmico de dados, ou seja, com uma aproximação de significados encontrados nas questões em que o participante se expõe livremente.

A coleta de dados se deu após a autorização do coordenador do curso selecionado e a posterior autorização do trabalho pelo Comitê de Ética em Pesquisa da Universidade de Mogi das Cruzes. Os participantes foram convidados, devidamente esclarecidos sobre suas participações e em seguida, em períodos que antecediam a aula, os dados foram coletados

\section{Resultados e Discussões}

Como interessava para a pesquisa apenas estudantes que trabalhassem, e muitos alunos decidiram colaborar, aceitou-se a participação de todos que atenderam ao convite de participação da pesquisa, por isso foram descartados 6 questionários, de alunos que não trabalhavam. O número de questionários que validaram a pesquisa foi de 37 , sendo a maioria mulheres $(67,56 \%)$ contra $(32,44 \%)$ de homens. Este quadro demonstra uma realidade bastante comum: a maioria destes estudantes são mulheres, uma tendência 
bastante comum no cenário atual, conforme demonstrou o Censo-IBGE 2010, o número de famílias chefiadas por mulheres vem crescendo o que exige da mulher mais capacitação profissional (Pnad/IBGE, 2011). Isso ratifica que as mulheres estão em constante pressão para sua inserção no mercado laboral brasileiro, ocupando muitas vezes lugares de destaque além de continuarem cuidando dos afazeres diários.

Identificou-se também que os homens, em sua totalidade não participam dos cuidados com as atividades domésticas, contra $28 \%$ das mulheres que além de estudar e trabalhar ainda cuida de suas casas. Isso denota que as mulheres que só exerciam papeis de donas de casa, mães e esposas, acumulam, atualmente, mais papeis e o mais importante, fora de casa, é ser um alicerce constituinte da força laboral. O quadro que se desenha é que trabalhadoras escolarizadas conquistaram bons empregos e acesso a carreiras antes ocupadas apenas pelos homens. Entretanto, permanece a responsabilidade pelas atividades dentro de casa e pelos cuidados com os filhos e demais parentes, mostrando continuidade de modelos familiares tradicionais, o que provoca sobrecarga para as novas trabalhadoras, sobretudo para as mães de crianças pequenas (BRUSCHINI, LOMBARDI e UMBEHAUN, 2006).

O Direito do Trabalho sempre buscou controlar a jornada de trabalho, evitando que esta fosse excessiva, causando danos à saúde do trabalhador. No século XIX a jornada chegava a atingir períodos de 12 a 16 horas, mesmo entre os menores e as mulheres, mas com a evolução da classe assalariada e a organização dos sindicatos, essas extensas horas foram combatidas, e a partir do século XX passa-se a ter em diversos países jornada máxima de dez horas diárias (DELGADO, 2006).

Nota-se, então, que um número considerado de trabalhadores permanece à disposição de seu empregador por um período de oito horas diárias e os demais entrevistados entre homens e mulheres trabalham em jornada reduzida de seis (06) horas 
correspondendo $45 \%$ dos entrevistados ou quatro horas correspondendo $24,34 \%$ por dia devido ao estágio.

Modernamente no Brasil, a partir da Constituição Federal de 1988, a jornada de trabalho sofreu alterações em seu artigo $7^{\circ}$ inciso XIII - duração do trabalho normal não superior a oito horas diárias e quarenta e quatro semanais, facultada a compensação de horários e a redução da jornada, mediante acordo ou convenção coletiva de trabalho, acompanhando o que determina a CLT em seu artigo 58.

Entre os participantes mais de $64 \%$ trabalha em jornadas de oito horas semanais, assim, observou-se que, de uma forma geral, todos dormem tarde e acordam cedo, considera-se que esse fato pode ser determinante entre um desempenho acadêmico, profissional desejável ou não, com reflexos na saúde física e mental, no tempo restante em que tem para se dedicar a familiares e/ou manter uma vida social ativa.

Diante disso e levando em consideração a necessidade de redução da jornada de trabalho a sociedade industrializada não necessitaria de tantas horas de trabalho, no entanto acrescenta Lunardi (2010) que seria impossível aplicar essa ideia nos dias atuais sem uma brusca alteração em nosso sistema, primeiro devido a uma busca desenfreada pelo capital e os incentivos ao consumo e depois porque essa ideia só pode ser concretizada se houver a participação do Estado na redução da carga tributária, nos encargos trabalhistas, pois com a redução o custo da produção se elevaria, pois outros trabalhadores seriam necessários para a mesma produção atual.

No todo, por hora para se garantir a melhoria das condições sociais se faz necessário que empregador e empregado possam juntos estabelecer parâmetros de satisfação e contentamento com objetivo de garantir dignidade plena. Pois segundo Marcellino (2012), o equilíbrio entre as práticas no contexto do lazer é fundamental para as pessoas desenvolverem suas potencialidades. 
Outro ponto levantado foi em relação ao tempo gasto no transporte, onde se pode observar que $25 \%$ do universo masculino fica 10 minutos no transporte público por dia, $33 \%$ ficam de 20 a 40 minutos e a grande maioria correspondendo $42 \%$ fica entre uma a duas horas no transporte para chegar ao trabalho.

Já o gênero feminino, uma não respondeu e duas responderam que vão a pé para ao trabalho, as demais enfrentam o transporte para ir ao trabalho todos os dias. Observase que $41 \%$ das participantes ficam entre uma a duas horas no transporte para chegar ao trabalho. Um dos grandes obstáculos para a dignidade do trabalhador é, sem dúvida o transporte coletivo nos grandes centros urbanos.

Grandes discussões acerca da mobilidade urbana têm varrido o país, e como o foco desta pesquisa são estudantes da RMSP, o Alto Tietê, considerou-se o deslocamento destes alunos para as outras cidades para o trabalho, como, por exemplo, São Paulo, para a qual se deslocam milhares de trabalhadores todos os dias usando trens, metrô e ônibus, nas escalas entre a residência e o trabalho, o trabalho e a universidade.

O Instituto de Pesquisa Econômica Aplicada (IPEA) divulgou um estudo sobre mobilidade urbana em regiões metropolitanas, mostrando os efeitos das condições de transporte na produtividade do trabalhador urbano, concluindo que quase $20 \%$ dos moradores de regiões metropolitanas gastam mais de uma hora para chegar ao trabalho. Isso se dá porque as cidades estão expandindo, fazendo com que as distâncias entre os locais de trabalho, as moradias e os centros de estudos, sejam atingidas com um enfrentamento de meios de transportes bastante ineficientes (IPEA, 2013).

A falta de qualidade e a dificuldade de mobilidade impede o trabalhadorestudante de aproveitar o tempo dentro dos meios de transporte para outras atividades de lazer, estudo ou outra atividade. Segundo o IPEA essa situação tem impacto negativo 
na produtividade da população, em razão do desgaste que esse trabalhador tem ao levar muito tempo e em condições muitas vezes desfavoráveis de transporte (IPEA, 2013).

No que se refere às horas de dedicação ao estudo fora do contexto de sala de aula, entre homens e mulheres $12,49 \%$ respondeu que estudava 2 horas por dia, dos $58,34 \%$ dos homens e $66,67 \%$ das mulheres respondeu que estudavam 3 horas diárias e $33,33 \%$ dos homens e $29,17 \%$ das mulheres respondeu que estudavam 4 horas por dia. Um participante não respondeu a esta questão, mas pode-se inferir que a maior parte dos estudantes estuda pelo menos 3 horas por dia.

Chama atenção o fato de que mesmo possuindo uma jornada de trabalho intensa, ou seja, $66,66 \%$ dos homens e $64 \%$ das mulheres, ressaltaram trabalhar 8 (oito) horas por dia, deslocar do trabalho para universidade e para casa, parte considerável dos estudantes $58,34 \%$ dos homens e $66,67 \%$ das mulheres respondeu que dedica pelo menos 3 horas diária de seu tempo ao estudo, por causa do tempo especificado, entendese que o aluno coloca apenas como tempo de estudo, seu período na universidade.

Santos; Cardoso e Reppold Filho (2008) afirmam que a necessidade de estudar e sempre se atualizar, o cuidado com a os afazeres domésticos reduz o tempo disponível ao lazer. Souza et al. (2014) obtiveram resultados com estudantes que relataram que a carga excessiva de trabalho como fator limitador das atividades de lazer, pois a preocupação com a inserção no mercado de trabalho exige dedicação às atividades universitárias.

Os participantes que afirmaram não ter tempo, sendo $16,65 \%$ dos homens explicam que trabalham nos finais de semana. Entre as participantes, $24 \%$ afirmaram não ter tempo, pois alegam que os afazeres domésticos, cuidar de filho, realizar os trabalhos exigidos pelos professores da universidade, estudar para concurso. Cantorani, Pedroso e Pilatti (2009) afirmam que a dedicação exaustiva às atividades profissionais 
vem comprometendo a qualidade de vida dos trabalhadores, consequentemente a sua dignidade.

Entre os participantes, uma delas expressa que tem muitos afazeres e falta de dinheiro, o que induz à conclusão de muitas atividades exigem investimento financeiro o que insere a compreensão do lazer do universo do consumo. A partir desta colocação depreende-se que uma barreira que impede as pessoas de desfrutar o lazer é a socioeconômica, pois ele virou sinônimo de consumo, criaram-se espaços destinados a proporcionar diversão para a família toda, não só ambientes fechados como shoppings, mas ambientes naturais como espaço para aventuras e banhos de mar (PINCO, 2005; QUEIROZ e SOUZA, 2009; SOUZA et al., 2014).

Areias e Borges (2011) afirmam que o poder aquisitivo tem sido o condicionante da prática do lazer, e assim pode-se inferir que certas opções apenas podem ser usufruídas por uma pequena parcela da população que possui condições financeiras de pagar pelos serviços e produtos oferecidos, indicando que para alguns lazer não é mera recreação ou ocupação do tempo livre.

Quando perguntados sobre as atividades de lazer mais frequentes, o participante poderia assinalar mais de uma opção. Entre os participantes do gênero masculino os esportes apontados foram: futebol, vôlei, musculação e academia, entre as participantes duas afirmaram praticar o ciclismo, foram ainda apontadas natação, patinação e musculação.

No tópico outros, os participantes apontaram cinema, baladas, viagens, bares, passeios a cachoeiras e a dedicação a um ministério eclesiástico, já as participantes apresentam demandas como conversar com a família, frequentar shoppings, cinemas e parques, ficar com os filhos, descansar, fazer trabalhos sociais, jogar vídeo game e ficar na Internet, uma participante afirmou que participa de concurso de canto. Como se vê, 
algumas atividades que ampliam a participação social já que envolvem esportes coletivos, atividades religiosas e com a família.

Queiroz e Souza (2009) ensinam que o lazer tem três funções: o descanso, o divertimento e o desenvolvimento, e é exatamente o que se observa no depoimento dos participantes já que alguns afirmam que descansam, outros se divertem porque saem para passeios a shoppings ou cinemas e parques, e um deles afirma que estuda para concurso, ou seja, aproveita para seu desenvolvimento pessoal.

Martins (2000) afirma que entre os universitários portugueses, os hábitos de leitura e de frequentar espetáculos ocupam um lugar muito pequeno nas preferências em comparação com a música e os programas de televisão. Assim, afirma o autor que muitos estudantes universitários são muito dependentes dos meios de comunicação de massa, e poucos praticam exercícios físicos ou esportes.

\section{Lazer e dignidade humana entre os universitários}

Para compreender a importância do lazer na vida dos estudantes universitários, buscou-se compreender nas respostas dos participantes a categoria da dignidade da pessoa humana. A partir da análise de conteúdo (BARDIN, 1977), buscaram-se palavras e expressões que faziam parte do campo semântico de dignidade humana, de modo que se compreendesse em que medida a sua compreensão de lazer trazia palavras e expressões que pudessem ser aproximadas aos inúmeros sentidos e significados do que sugere a expressão dignidade humana, como se vê no Quadro 1 a seguir: 
Quadro 1. Como os estudantes compreendem a importância do lazer na constituição de sua dignidade

\begin{tabular}{|c|c|}
\hline MASCULINO & FEMININO \\
\hline ....tempo para você mesmo. & $\begin{array}{l}\text { 1. Sintonia com a família, proporcionando bem } \\
\text { estar }\end{array}$ \\
\hline $\begin{array}{l}\text { 2. Descanso mental impossível de } \\
\text { atingir por outros meios. }\end{array}$ & $\begin{array}{l}\text { 2. Bem estar, distração, me faz esquecer os } \\
\text { problemas e melhorar o dia }\end{array}$ \\
\hline $\begin{array}{l}\text { 3. Esquecer dos momentos de stress } \\
\text { decorrentes de uma semana cansativa. }\end{array}$ & $\begin{array}{l}\text { 3. .... acalma o corpo e a mente e me prepara } \\
\text { para jornada. }\end{array}$ \\
\hline $\begin{array}{l}\text { 4. Importante na saúde pelo fato de } \\
\text { tirar o stress do dia a dia }\end{array}$ & Importante para retirar stress. \\
\hline $\begin{array}{l}\text { 5. Despreocupação sobre os deveres } \\
\text { e obrigações }\end{array}$ & $\begin{array}{l}\text { 5. Influenciam meu comportamento no local de } \\
\text { trabalho e universidade, }\end{array}$ \\
\hline $\begin{array}{l}\text { 6. Todos precisam fazer algo que } \\
\text { gostem seja o que for. }\end{array}$ & Recarregar as energias e enfrentar as batalhas. \\
\hline $\begin{array}{l}\text { 7. Trabalham muito e ganham } \\
\text { pouco, por isso o lazer é importante } \\
\text { para aproveitar com a família. }\end{array}$ & $\begin{array}{l}\text { 7. Relaxar e esquecer as preocupações e correrias } \\
\text { do dia a dia. }\end{array}$ \\
\hline $\begin{array}{l}\text { 8. Vida Saudável, momentos de } \\
\text { distração, que alivia stress do dia a dia. }\end{array}$ & $\begin{array}{l}\text { 8. ...podemos descansar e fazer coisas que } \\
\text { gostamos. }\end{array}$ \\
\hline 9. Momento de distração & $\begin{array}{l}9 . \quad \text { Momento de opção por } \text { atividades } \\
\text { obrigatórias... }\end{array}$ \\
\hline $\begin{array}{l}\text { 10. Ajuda a manter firme e disposto } \\
\text { para com a jornada de trabalho e estudo. }\end{array}$ & $\begin{array}{l}\text { 10. Descontração, que me permite relaxar e } \\
\text { esquecer os problemas do dia a dia. }\end{array}$ \\
\hline \multirow[t]{6}{*}{$\begin{array}{l}\text { 11. Passar tempo com filhos e esposa } \\
\text { em passeios. }\end{array}$} & $\begin{array}{l}\text { 11. Relaxar o corpo, alma, sentir a natureza, } \\
\text { renovar as energias. }\end{array}$ \\
\hline & Descansar, aproveitar com a família. \\
\hline & Faz bem para saúde. \\
\hline & Satisfação pessoal. \\
\hline & Melhorar, carregar energias e distrair a mente. \\
\hline & Prazer para fazer novas coisas no meu dia. \\
\hline
\end{tabular}

Os diferentes tipos de trabalhadores e mesmo os que não trabalham ou que estão desempregados, percebem o tempo livre de maneira diferente (CAMPOS, SILVESTRE e LOPES, 2004), assim também as diferentes camadas sociais o fazem, pois têm necessidades de ocupação do tempo livre de forma diferenciada.

Quando os participantes apontam expressões como "relaxar o corpo e a alma", "prazer para fazer novas coisas", "acalma o corpo e a mente", "faz bem para a saúde” "renovar energias”; “...tempo para você mesmo”; é clara a noção que cada um tem de preservar sua dignidade. $\mathrm{O}$ estresse da vida atribulada faz emergir uma noção de lazer demonstra que ele é um componente de uma vida de qualidade, de bem estar e de 
dignidade. Neste rol, percebe-se a importância que atribuem ao lazer, por ser um tempo que lhes permite esquecer-se dos problemas, até porque como eles mesmos afirmam “trabalham muito e ganham pouco, por isso o lazer é importante para aproveitar com a família”. Queiroz e Souza (2009) afirmam que a prática do repouso, de dormir e descansar, até pouco tempo, não eram consideradas atividades de lazer.

Se por um lado, as políticas sociais brasileiras previstas no artigo $6^{\circ}$ da Constituição Federal vêm solidificando áreas como saúde, educação, alimentação, trabalho, alimentação, segurança, em virtude da descentralização e da reivindicação da população, por outro, o direito ao direito ao lazer não entrou, ainda, no rol das políticas sociais e ainda não ocupa mais espaço nesse debate, é necessário o incremento das políticas de cultura e turismo.

A proteção ao trabalhador foi a que despontou mais interesse desde de a entrada da humanidade no panorama da produtividade e do consumo. $\mathrm{O}$ trabalhador enriquece o estado de duas formas: produz, faz os bens circularem nacional e internacionalmente, aumentam o poder político e econômico dos Estado e por isso foi e continua sendo atores de pressão para a inserção de políticas de proteção para eles mesmos que, atualmente, se estendem a toda a população, veja-se aí a saúde e a educação. É o dinheiro da previdência social que permite muitos desdobramentos para a proteção social no estado democrático que se vive atualmente. Mas, neste quadro, não coube ao lazer um espaço privilegiado, não houve a compreensão de que o tempo de lazer apresenta-se como mediador entre a cultura de uma sociedade e as reações de um indivíduo em sua vida cotidiana.

Por suma, se o trabalhador lutasse pelo lazer, por tempo livre, como lutou ao longo da história por melhores condições de trabalho, jornadas mais flexíveis, melhores salários, conseguiria alcançar mais respeito em sua dignidade. 


\section{Considerações Finais}

Como se viu, o princípio da dignidade da pessoa humana é multifacetado, emerge de diferentes atividades da vida humana e se expressa basicamente em alguns pilares que são o bem estar que abrange o cenário familiar, social, econômico e cultural do sujeito, entre outros e a qualidade de vida, estes, por sua vez, são as duas faces de uma mesma moeda: o mínimo existencial de cada um.

O que norteou este trabalho foi justamente encontrar estudantes da área de Gestão em Recursos Humanos que irão, no mercado de trabalho num futuro próximo, estar atentos à dignidade do trabalhador e dos quais, várias vezes, se pode ouvir várias reclamações de que não têm acesso ao lazer que desejam, pois suas atividades diárias os impedem de ter uma melhor qualidade de descanso, de lazer, de acesso à cultura e ao entretenimento.

Diante dos vários aspectos destacados, pode-se perceber a necessidade de compreensão do direito ao lazer como um elemento necessário para a dignidade humana, da mesma forma que se faz necessário compreender quais atividades humanas são entendidas como lazer, pois a excessiva jornada do homem ocidental o distanciou destes conceitos.

O tempo livre foi se ressignificando e o trabalhador vê atualmente seu tempo livre como mais um obstáculo para poder empreender um projeto de lazer, já que muitos equipamentos culturais que trazem diversos tipos de lazer, cultura e entretenimento, são privados, trazem custo e fazem parte do rol da indústria do lazer e do turismo.

Os resultados demonstraram que a maioria dos estudantes têm pouco tempo livre ao longo da semana. Suas atividades de lazer são estar com a família, com os amigos e descansar. Alguns descrevem outras atividades mais específicas como passeios e 
estudos para uma nova oportunidade de trabalho, mas basicamente, o tempo que lhes sobra é para relaxar, recuperar as energias dispensadas na semana pela sobrecarga de tarefas, o que impede que ele tenha uma vida plena em sua dignidade.

Pode-se perceber que muitos dos entrevistados reclamaram não ter tempo livre, ou ainda não possuírem condições financeiras de desfrutar esse tempo, pois há uma sobrecarga do tempo vinculado a atividades obrigatórias.

Ademais, há ainda um grande tempo gasto no deslocamento de casa para o trabalho, como apontado, o que dificulta consideravelmente a qualidade de vida impedindo a realização de outras atividades, dentre elas o lazer.

É fácil notar que as soluções para a efetividade do direito ao lazer se relacionam com esferas sociais e econômicas, pois hoje em dia o ser humano está muito mais voltado ao consumo, ao ter cada vez mais e para isso necessita produzir mais no campo econômico, profissional, do que preocupado com sua qualidade de vida.

Para tanto a conclusão que se chega é que a concretização dos direitos sociais, entre eles o lazer, por meio de políticas sociais é essencial para o exercício da cidadania. É preciso repensar o papel do lazer dentro do princípio da dignidade humana, qual o se peso e seu significado, seja socialmente, economicamente, profissionalmente, pois as políticas públicas de lazer só serão reconhecidas pela sociedade e pelo Estado, quando se compreender a necessidade de que o lazer é um dos componentes fundamentais para a qualidade de vida e o bem estar dos trabalhadores.

\section{Referências}

ALVES, Juliana. M. Trabalho e trabalhadores no segundo governo Vargas: as greves como um "antidireito" (1951-1954). Rev. História, São Paulo. n. 172. p. 367-396, 2012. 
AQUINO, Cássio Adriano Braz; MARTINS, José Clerton de Oliveira. Ócio, lazer e tempo na sociedade do consumo e do trabalho. Revista Mal-Estar e Subjetividade. Fortaleza, v. 7, n. 2, p. 479-500, set. 2007.

AREIAS, Keni T.V., BORGES, Carlos N. Ferreira. As políticas públicas de lazer na mediação entre Estado e Sociedade: possibilidades e limitações. Rev. Bras. Ciências dos Esportes. Florianópolis. v.33. no. 3, p. 573-588 jul/set 2011.

ARRETCHE, Marta. T.S. Emergência e desenvolvimento do welfare state: teorias explicativas. Boletim Informativo e Bibliográfico em Ciências Sociais, São Paulo, v. 39, p. 3-40, 1995.

BACAL, S. Lazer - teoria e pesquisa. São Paulo; Loyola, 1988.

BARDIN, L. Análise de Conteúdo. 7. ed. São Paulo: Persona, 1977.

BARROS, Alice Monteiro de. Curso de direito do trabalho. 7. ed. São Paulo: LTr, 2011.

BRASIL. Constituição da República Federativa do Brasil - 18. ed., rev., ampl. e atual. São Paulo: Saraiva, 2013.

Instituto Brasileiro de Geografia e Estatística. IBGE. PNAD 2012. Disponível em: www.ibge.gov.br. Acesso em: 03 jul. 2014

Instituto de Pesquisa Econômica Aplicada. IPEA. Indicadores de mobilidade urbana da Pnad 2012. Rio de Janeiro, 2013.

BRUSCHINI,C. LOMBARD I, L.R e UMBEHAUN,S. Trabalho, renda e políticas sociais: Avanços e desafios. In: CEPIA; UNIFEM; Ford Foundation. (Org.). O progresso das mulheres no Brasil. Disponível em: http://www.mulheresnobrasil.org.br/. Acesso em: 10 jun. 2014.

CALVET. Otávio A. O direito ao lazer nas relações de trabalho. s/d. Disponível em: http://www.calvo.pro.br/media/file/colaboradores/otavio_calvet/otavio_calvet direito_a o_lazer.pdf. Acesso em: 22 jul. 2012.

CAMPOS, M.B.L., SILVESTRE, M.C., LOPES, R.H.B. O professor universitário - um estudo sobre atividade acadêmica e tempo livre. Universidade e Sociedade. v.14, n. 34, Out. 2004.

CANTORANI, J.R.H., PEDROSO, B., PILATTI, L.A. As esferas do trabalho e lazer e os desafios e tendências da qualidade de vida. EFdeportes.com Revista Digital. Buenos Aires. v. 14, n. 132, maio de 2009.

COUTO, B. R. O Direito Social e a Assistência Social na Sociedade Brasileira: uma equação possível? São Paulo: Cortez, 2004.

DAL COL, Helder Martinez. O princípio da dignidade da pessoa humana, o direito ao trabalho e a prevenção da infortunística. $\mathrm{s} / \mathrm{d}$ In. http://egov.ufsc.br/portal/sites/default/files/anexos/7492-7491-1-PB.pdf. Acessado em 22.07.2015. 
DALFOVO, M. S.; LANA, R. A.; SILVEIRA, A. Métodos quantitativos e qualitativos: um resgate teórico. Revista Interdisciplinar Científica Aplicada, Blumenau, v.2, n.4, p.01- 13, Sem II. 2008.

DELGADO, Gabriela Neves. Direito fundamental ao trabalho digno. São Paulo: LTR, 2006.

DUMAZEDIER, J. Lazer e cultura popular. São Paulo: Perspectiva, 1976.

LUNARDI, A. Função Social do Direito ao Lazer nas Relações de Trabalho. São Paulo: LTR, 2010.

MARCELlinO, N. C. Estudos do lazer: uma introdução. 4. ${ }^{a}$ ed. Campinas: Autores Associados, 2012.

MARTINS, A.M. Estudantes Universitários, lazer e práticas socioculturais: estudo de caso. CONGRESSO PORTUGUÊS DE SOCIOLOGIA. Associação Portuguesa de Sociologia, $4 . \quad$ Anais... 2000.4 Disponível em: http://www.aps.pt/cms/docs prv/docs/DPR462df6816b73a_1.PDF. Acesso em: 03 jul. 2014.

MIRAGLIA, Lívia Mendes Moreira. O direito do trabalho e a dignidade da pessoa humana - pela necessidade de afirmação do trabalho digno como direito fundamental. ENCONTRO NACIONAL DO CONPEDI, 19. Anais... Fortaleza 09 a 12 de Junho de $2010 . \quad$ Disponível em: http://www.conpedi.org.br/manaus/arquivos/anais/fortaleza/3828.pdf. Acesso em: 27 set. 2014.

PINCO, T. A sociedade capitalista e a crescente busca pelas atividades naturais de lazer. Rev. digital EFD Esportes. Buenos Aires, v. 10, n. 89. Out. 2005.

POCHMANN, M. Proteção Social na periferia do Capitalismo - considerações sobre o Brasil. São Paulo em Perspectiva, v.18,vn. 2, p. 3-16, 2004.

QUEIROZ, M.N.G. \& SOUZA, L.K. Atividades de lazer em jovens e adultos: um estudo descritivo. Licere, Belo Horizonte, v. 12, n. 3, p. 1-21. set 2009.

SANTOS, E.S., CARDOSO, M.F.S., REPPOLD FILHO, F.S. Obrigações: com o trabalho doméstico familiar e atividades de lazer de estudantes de Canoas/RS. Rev. Eletrônica da Esc. de Ed. Física e Desportos, UFRJ, v. 4, n. 1 Jan/Jun 2008.

SARLET, Ingo Wolfgang. Dignidade da Pessoa Humana e Direitos Fundamentais na Constituição Federal de 1988. 5. ed. Porto Alegre: Livraria do Advogado, 2012.

SOUZA, Iorani R. et al. A experiência de lazer de estudantes do curso de licenciatura em educação física de uma instituição de ensino superior do Distrito Federal. Pensar a prática. Goiânia. v.17, no. 1, pp.01-294. jan/mar 2014.

SOUZA, P.B. \&MISAILIDIS, M.G.L.M. O direito ao lazer e a dignidade humana do trabalhador frente à economia sem fronteiras. $10^{\circ}$. Mostra Acadêmica UNIMEP. 2012.

em: 
http://www.unimep.br/phpg/mostraacademica/anais/10mostra/5/170.pdf Acesso em: 03 jul. 2014.

STUCHI, V.H.N. O trabalho decente e a dignidade da pessoa humana. In: FACHINETTI Junior, V. M. Ensaios jurídicos contemporâneos - Dignidade da Pessoa Humana. São Paulo: IXTLAN, 2011.

VIANNA, Francisco, JK - A Saga de um Herói. São Paulo: Companhia Editora Nacional, 2006.

VIEIRA, E. O trabalho: breve visão da concepção de castigo da antiguidade cristã, valor social afirmado na Encíclica Rerum Novarum no século XIX e despontar do século XXI como valor bioético. Revista Bioéthika. Centro Universitário São Camilo, São Paulo, v.4, n. 3, p. 350-353, 2010.

\section{Endereço das Autoras:}

Carla Alessandra Branca Ramos Silva Aguiar

Núcleo de Ciências Sociais Aplicadas

Av. Dr. Cândido Xavier de Almeida e Souza, 200

Mogi das Cruzes - SP - 08780-911

Endereço Eletrônico: carla@umc.br

Luci Mendes de Melo Bonini

Núcleo de Ciências Sociais Aplicadas

Av. Dr. Cândido Xavier de Almeida e Souza, 200

Mogi das Cruzes - SP - 08780-911

Endereço Eletrônico: luci.bonini@umc.br 